
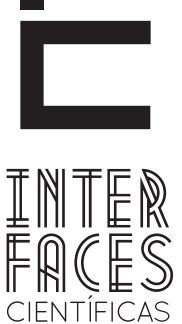

DIREITO

\title{
A IMPORTÂNCIA DOS PRINĆ́PIOS DA LIVRE CONCORRÊNCIA E DA LIVRE INICIATIVA PARA MANUTENÇ̃̃o DA ORDEM ECONÔMICA NO BRASIL
}

Andresa Semeghini Pereira ${ }^{1}$
Adeneele Garcia Carneiro ${ }^{2}$

\section{RESUMO}

0 presente trabalho analisou os princípios constitucionais da livre iniciativa e da livre concorrência, para compreender a conjugação dos mesmos em benefício da ordem econômica, e responder ao questionamento que cerne a pesquisa, quanto à essencialidade dessa conjugação como preceito fundamental ou mera enunciação legal. Mediante a adoção do procedimento dedutivo, amparado por meio do uso de material bibliográfico, pretendeu-se aludir uma contribuição que visou estimular o senso crítico em relação aos mecanismos utilizados pelo Estado para concretizar a previsão ora elucidada. Deste modo, de forma sucinta abarcou-se incialmente a construção histórica da intervenção econômica pelo Estado até então conso- lidadas no ordenamento constitucional, para que assim, se justifique o sentido harmônico dos princípios da livre iniciativa e concorrência, e por fim possam-se conhecer as estruturas infraconstitucionais que sistematicamente efetivam a atuação estatal em defesa da concorrência em conformidade aos ditames principiológicos, a exemplo do direito antitruste que traz disposições de cunho preventivo, repreensivo e educativo exercidos pelos órgãos de defesa da concorrência.

\section{PALAVRAS-CHAVE}

Ordem Econômica. Livre Iniciativa. Livre Concorrência. 


\section{ABSTRACT}

This study analyzed the constitutional principles of free enterprise and free competition, to understand the combination thereof for the benefit of the economic order, and answer the question that the research core, about the essential nature of this combination as a fundamental precept or mere legal enunciation. By adopting the deductive procedure, supported through the use of publications, it was intended to allude a contribution which aimed to encourage critical thinking on the mechanisms used by the state to carry out the forecast now elucidated. Thus, briefly embraced it-initially the historical construction of economic intervention by

\section{RESUMEN}

Este estudio examinó los principios constitucionales de la libre iniciativa y la libre competencia, para entender la combinación de los mismos en beneficio del orden económico, y responder a la pregunta que es núcleo de la investigación, sobre la naturaleza esencial de esta combinación como un precepto fundamental o mera enunciación legal. Al adoptar el procedimiento deductivo, con el apoyo a través del uso de material bibliográfico, se pretendía aludir una contribución que tiene por objetivo fomentar el pensamiento crítico sobre los mecanismos utilizados por el Estado para llevar a cabo la previsión ahora dilucidada. Así, en pocas palabras, se contuvo inicialmente la construcción histórica de la intervención económica del Estado hasta the State until then consolidated the constitutional order, so that, justified the harmonic sense of the principles of free enterprise and competition, and finally one can know-the infra structures that systematically actualize the state action in defense of competition in accordance with the dictates of logical principles, such as the antitrust law that brings preventive nature rules, reprehensible and educational exercised by the organs of antitrust.

\section{KEYWORDS}

Economic Order. Free Initiative. Free Competition.

entonces consolidada en el orden constitucional, para que así, se justifique el sentido armónico de los principios de la libre iniciativa y competencia. Y finalmente, se pueda saber las estructuras infra constitucionales que sistemáticamente hacen valer la actuación del Estado en defensa de la competencia en conformidad a los órdenes de principio, como el derecho de la competencia que trae reglas de carácter preventivo, reprensivo y educativo ejercidas por los órganos de defensa de la competencia.

\section{PALABRAS CLAVE}

Orden económico. Libre iniciativa. Libre competencia. 


\section{INTRODUÇÃO}

Em face da organização econômica legalmente regulamentada pelo Estado como reflexo da Democracia, a Constituição da República Federativa do Brasil, promulgada em outubro de 1988, incorporou título específico da "Ordem Econômica e Financeira" que estabelece os princípios gerais, as garantias, e os limites a serem seguidos, pelo direito econômico.

A Ordem Econômica foi consolidada legislativamente por meio da construção histórica de pactuação do modelo de atuação Estatal, enquanto interventor na economia, que se deu, em detrimento dos diferentes contextos políticos e econômicos do país. Para compreensão dessa construção, no primeiro capítulo faz-se um retrospecto histórico das Constituições já vigentes, salientando os aspectos gerais que influenciaram o intervencionismo do Estado na economia, suas espécies e os elementos formadores da atual conjuntura.

Deste modo, será possível compreender os objetivos, fundamentos e os princípios norteadores da Ordem Econômica de que trata a Constituição de 1988, considerando a ordem normativa e sistemática do Direito, respeitado o corte metodológico em que se pautou o presente estudo, para abordar, mais especificamente, os princípios da Livre Iniciativa e Livre Concorrência, enquanto pilares da Ordem Econômica que emanam subsídios legais para regularem a ingerência estatal no mercado econômico.

No segundo capítulo far-se-á o delineamento dos princípios da livre iniciativa e livre concorrência, para compreender a essencialidade de sua internalização no ordenamento, de forma ampla, sopesando a abrangência axiológica a que se propõe, para que assim, possam-se verificar as implicações na seara constitucional e infraconstitucional.

No terceiro capítulo, citam-se mecanismos de efetividade possíveis, dada à importância da operacionalização do controle constitucional e infraconstitucional no desenvolvimento econômico do País. Amparado pelo breve estudo do papel da lei antitruste $n^{0} 12.529 / 11$ que possui importante cargo nessa temática, sob a missão de evitar distorções de mercado que firam a livre concorrência por meio do controle exercido pelos órgãos de defesa da concorrência, em especial pela atuação do Conselho Administrativo de Defesa Econômica (CADE).

Objetiva-se, no fim, deixar claro, a importância dos princípios que constituem vetor primordial no direito em especial à Ordem Econômica, devendo ser compreendidos e aplicados de forma harmônica, em decorrência lógica do princípio hermenêutico da unidade constitucional, e seja possível responder ao questionamento proposto, quanto à configuração da conjugação dos princípios da livre iniciativa e livre concorrência, como elemento fundamental ou mera enunciação legal.

Para tanto, o estudo desenvolver-se-á com o amparo de material bibliográfico, por meio de averiguação de expressão instrumental, como análise e fichamento de documentos sobre o tema, e a apresentação do desenvolvimento do objeto da presente pesquisa dar-se-á mediante a adoção do procedimento dedutivo.

\section{INTERVENCIONISMO ESTATAL NA ORDEM ECONÔMICA BRASILEIRA}

No plano da positivação, a intervenção estatal na ordem econômica não se faz instituto inédito da Constituição Federal de 1988, uma vez que, ainda que de forma tímida, essa temática encontrou respaldo em diplomas constitucionais anteriores. Nesse sentido, cabe salientar a construção histórico-jurídica do tema na seara constitucional, para compreender a atual conjuntura da ordem econômica prevista na Lei Maior vigente.

Para tanto, cumpre-se recorrer ao primeiro Estatuto Constitucional do Brasil outorgado em 1824, conhecido como Carta Imperial, regulado pela figura política do poder Moderador existente a época. Tal dispositivo apresentava aspectos iminentemente liberais, reflexo do modelo econômico vivido, evidenciado, por exemplo, na plenitude e falta de limitações ao direito de propriedade.

Não obstante as raízes do liberalismo e a falta de regulações quanto à intervenção estatal, a Carta Polí- 
tica de 1824 apontou pequenos esforços despendidos para tanto, ainda que de forma vedada, confirmados principalmente no que tange o posicionamento Estatal quanto às tarifas alfandegárias e a presença da intervenção do poder público mesmo que no âmbito de tributação, o que denota a necessidade de resguardo e impossibilidade de total inércia em sua atuação.

Esse modelo de 1824 reinou por muitos anos e foi reafirmado no Texto Constitucional de 1891 que em seu artigo 72, § 17 assim dispôs: "O direito de propriedade mantém-se em toda a sua plenitude, salva a desapropriação por necessidade ou utilidade pública, mediante indenização prévia” (BRASIL, 1891). Tal texto legal da época denota o notório respaldo jurídico para o liberalismo que visava afastar o Estado das atividades econômicas.

Ocorre que, mesmo sem grandes avanços em 1891, o intervencionismo do Estado existia, ainda que presente como estratégia mercadológica e econômica do País para se manter em evidência na produção e comercialização de café, no cenário internacional.

A mudança nesse tocante ocorreu apenas com o advento do grande marco da Ordem Econômica por meio da Constituição de 1934, que trouxe expressamente o Capítulo IV, específico para tratar do tema, instituindo assim o constitucionalismo econômico legalmente reconhecido, que veio intrínseco, inclusive no preâmbulo do dispositivo que dispôs sobre a diretriz do bem-estar social e econômico, Brasil, 1934:

Nós, os Representantes do Povo Brasileiro, pondo a nossa confiança em Deus, reunidos em Assembléia Nacional Constituinte para organizar um regime democrático, que assegure à Nação a unidade, a liberdade, a justiça e o bem-estar social e econômico, decretamos e promulgamos a seguinte CONSTITUIÇÃO DA REPÚBLICA DOS ESTADOS UNIDOS DO BRASIL. (Grifo do autor).

Desta feita, a Constituição de 1934 (BRASIL, 1934), foi a primeira a consagrar princípios e normas específicos à ordem econômica, apesar de pequenos esforços anteriores terem sidos fundados, no que tange a intervenção do Estado na economia, instaurando assim, com essa conjuntura diferenciada o Estado do bem estar social.
Art. 115. A ordem econômica deve ser organizada conforme os princípios da justiça e as necessidades da vida nacional, de modo que possibilite a todos existência digna. Dentro desses limites, é garantida a liberdade econômica. Parágrafo único. Os poderes públicos verificarão, periodicamente, o padrão de vida nas várias regiões do país. (Grifo nosso).

Com o liberalismo em queda e o Estado do bem-estar social em ascensão, alguns resquícios do antigo modelo ainda são percebidos como, por exemplo, ao direito de propriedade, apesar de agora não ser mais pleno e haver limitações voltadas para o social, ainda abre margem para interpretações liberais. Por sua vez, o dispositivo Constitucional durou pouco tempo, em decorrência do golpe político sofrido que resultou em outra Carta em 1937.

Observa-se assim, a influência de fatores como: política, o modelo de governança, bem como do contexto econômico na criação do direito posto. Deste modo, diversos aspectos históricos, inclusive anteriores a 1934, até mesmo internacionais, influenciaram o tratamento da intervenção estatal no instituto jurídico Brasileiro, a título de exemplo tem-se a Constituições, Mexicana, de 1917 e a Constituição Alemã (de Weimar), de 1919, fortes influências para estruturação constitucional do Estado ativo no desenvolvimento social.

Fato é que, apesar de durar pouco tempo a Constituição de 1934 denotou expressivos avanços jurídicos, sociais e políticos, infelizmente prejudicada em detrimento da Carta de 1937 que comprovou regressão fática, de cunho completamente centralizador. Tal regramento no campo econômico objetivava o sustento econômico direto pelo Estado, como forma de suprir as atividades privadas. Acerca do momento histórico, diversas reestruturações foram sendo elaboradas no campo político, e somente em 1946 foi inaugurada uma nova Assembleia Constituinte e consequentemente foi promulgada nova Lei Máxima, que optou por manter preceitos da Constituição de 1934, no tocante aos valores sociais intrínsecos no título retomado na Ordem Econômica, vislumbrando em seu bojo os princípios da livre iniciativa e indícios a livre concorrência e o exercício desses pelo Estado. 
O Art. 145 e 148, do Texto Constitucional de 1946 (BRASIL, 1946), estabeleceu:

\begin{abstract}
A ordem econômica deve ser organizada conforme os princípios da justiça social, conciliando a liberdade de iniciativa com a valorização do trabalho humano. Parágrafo único. A todos é assegurado trabalho que possibilite existência digna. O trabalho é obrigação social. (Grifo nosso).

[...]

Art 148 - A lei reprimirá toda e qualquer forma de abuso do poder econômico, inclusive as uniões ou agrupamentos de empresas individuais ou sociais, seja qual for a sua natureza, que tenham por fim dominar os mercados nacionais, eliminar a concorrência e aumentar arbitrariamente os lucros. (Grifo nosso).
\end{abstract}

Apesar do evidente retorno ao avanço, diversas alterações no cenário político ocorreram em meados de 1960, fatos que influenciaram fortemente a próxima Carta de 1967, outorgada, e que pela influência do governo popular trouxe uma nova visão para a ordem econômica, arraigada por uma intervenção exagerada do Estado, apesar de conter em seu texto, ainda que formalmente os princípios norteadores no plano do direito positivo.

Logo, em 1969, por meio da Emenda Constitucional $n^{0} 1$, de 17 de outubro, a ideia de unidade ainda estava presente, dito isso, por ser esse texto considerado por alguns como uma nova Carta, pelas modificações na forma de governo e de Estado, pelos quais estava passando o país à época, de qualquer forma, no tocante à ordem econômica a referida emenda trouxe alguns esclarecimentos.

Os esclarecimentos cernem a inserção do modo pelo qual o Estado deveria intervir na economia, no título "Da Ordem Econômica e Social”, o mesmo trouxe em seu bojo a importância da intervenção Estatal na economia privada, para atingir a finalidade a que se propõe a referida regulação, qual sejam a realização do desenvolvimento nacional e a justiça social, baseado nos princípios constitucionais do título, com possibilidade, ainda, do princípio da subsidiariedade, ou seja, a atuação direta na ordem econômica pelo poder público era admitida subsidiariamente.
Tais modificações cernem guarida para a formação da regulação hoje evidenciada na Constituição da República Federativa do Brasil, promulgada em outubro de 1988, que prevê título VII, “Da Ordem Econômica e Financeira", influenciadas pelas modificações históricas do Direito Econômico nas Constituições anteriores, sendo que, "o que se extrai da leitura despida de senso crítico, dos textos constitucionais, é a indicação de que o capitalismo se transforma na medida em que assume novo caráter, social” (GRAU, 2010, p. 56-57).

A Constituição da República de 1988, arraigada pelas tendências da globalização, traz a Ordem Econômica e Financeira como perpetuação da correlação entre Direito e Economia, primada por limites sociais, com finalidade de resguardo do bem comum em detrimento de qualquer interesse individual, ainda que do Estado, como preceitua o Art. 170 (BRASIL, 1988):

\footnotetext{
Art. 170. A ordem econômica, fundada na valorização do trabalho humano e na livre iniciativa, tem por fim assegurar a todos existência digna, conforme os ditames da justiça social, observados os seguintes princípios: I- soberania nacional;

II- propriedade privada;

III- função social da propriedade;

IV- livre concorrência:

$\mathrm{V}$ - defesa do consumidor;

VI- defesa do meio ambiente, inclusive mediante tratamento diferenciado conforme o impacto ambiental dos produtos e serviços e de seus processos de elaboração e prestação;

VII- redução das desigualdades regionais e sociais;

VIII- busca do pleno emprego;

IX- tratamento favorecido para as empresas de pequeno porte constituídas sob as leis brasileiras e que tenham sede e administração no País;

Parágrafo único. É assegurado a todos o livre exercício de qualquer atividade econômica, independentemente de autorização de órgãos públicos, salvo nos casos previstos em lei. (Grifo do autor).
}

Os princípios não configuram mero norte de atuação, uma vez, que a compreensão sistemática do ordenamento pautado na Constituição como máximo do direito, delega toda e qualquer matéria em seu bojo coerência normativa. Em destaque aos princípios da livre iniciativa e livre concorrência, previsões essas, 
que visam garantir o desenvolvimento e o enriquecimento com foco no fortalecimento do modo de produção capitalista, se pode afirmar que as limitações tanto a iniciativa privada quanto ao Poder Público, consolida o resguardo ao interesse social.

Quanto aos princípios da Ordem Econômica, André Ramos Tavares (2013, p. 134) assim compreende:

\begin{abstract}
Estes princípios perfazem um conjunto cogente de comandos normativos, devendo ser respeitados e observados por todos os "Poderes", sob pena de inconstitucionalidade do ato praticado ao arrepio de qualquer deles. Portanto, serão inadmissíveis (inválidas) perante a ordem constitucional as decisões do Poder Judiciário que afrontarem estes princípios, assim como as leis e qualquer outro ato estatal que estabelecer metas e comandos normativos que, de qualquer maneira, oponham-se ou violem tais princípios.
\end{abstract}

Deste modo, percebe-se a construção histórica da estrutura jurídica na mais alta órbita, para a atual conjuntura configuram significativo marco da passagem de um Poder Público que pouco ou nada pratica, para um Estado interventor mínimo, ou seja, aquele que o faz quando é necessário, limitado por premissas principiológicas e normativas, não é algo inédito, mas sim, uma construção que mais que mera previsão legal, merece completa observação na aplicação da lei.

\section{HARMONIA PRINCIPIOLÓGICA - LIVRE INICIATIVA E LIVRE CONCORRÊNCIA}

Partindo da concepção de possibilidade de intervenção estatal no domínio econômico em respeito aos limites jurídicos, e em consonância aos ditames constitucionais, como a livre iniciativa e a livre concorrência, faz-se necessário desdobrar a conceituação dos referidos princípios que exprimem a liberdade e as garantias que norteiam a Ordem Econômica, para estabelecer a correlação entre eles, em detrimento da efetiva solução para os desajustes mercadológicos.

A Carta Magna de 1988 reserva papel primordial à regulação da livre iniciativa, considerando que o referido princípio, além de norte da Ordem Econômica, perfaz, também, fundamento da República Federativa do Brasil, ínsito no artigo $1^{\circ}$ da que assim dispõe (BRASIL, 1988):
Art. $1^{\circ} \mathrm{A}$ República Federativa do Brasil, formada pela união indissolúvel dos Estados e Municípios e do Dis- trito Federal, constitui-se em Estado Democrático de Direito e tem como fundamentos:
I - a soberania;
II - a cidadania;
III - a dignidade da pessoa humana;
IV - os valores sociais do trabalho e da livre iniciativa;
V - o pluralismo político. (Grifo do autor).

A livre iniciativa pode ser compreendida em consenso com o direito à liberdade, consubstanciado no artigo $5^{\circ}$, e ambos como forte base da liberdade de lançar-se ao mercado e exercer atividade econômica, considerando ainda o sentido, não só do ingresso ao mercado, mas a permanência nele, deste modo, estaria por sua natureza, interligado as atividades relevantes economicamente, com a finalidade de assegurar igualdade de condições da inciativa privada perante a concorrência, quando assegurado seu ingresso ao mercado, ou perante o Estado, na sua forma negativa de não intervenção estatal amparada legislativamente.

0 postulado da livre iniciativa possui importante papel como vetor da conotação normativa de liberdades conexas da inciativa privada econômica, do ponto de vista do direito econômico e da ordem político-econômica do país, "a livre inciativa revela a adoção política da forma de produção capitalista, como meio legítimo de que se podem valer os agentes sociais no Direito Brasileiro" (TAVARES, 2013, p. 33).

Certamente qualquer reducionismo na seara dos princípios constitucionais, deve ser avaliado cuidadosamente, uma vez que a função axiológica a que esse se propõe é tamanha, nesse sentido Eros Grau (2010, p. 204) se posiciona quanto à abrangência do princípio:

[...] livre iniciativa não se resume, aí, a "princípio básico do liberalismo econômico" ou a "liberdade de desenvolvimento da empresa" apenas - à liberdade única do comércio, pois. Em outros termos: não se pode visualizar no princípio tão-somente uma afirmação do capitalismo. 
A notável importância é consubstanciada no sentido de compreender a livre iniciativa, "tomando em consideração um ponto de vista equitativo, mais consentâneo com os ideais democráticos e de justiça social, também fundamentos do Estado brasileiro" (PETTER, 2005, p. 167).

Para compreensão das implicações e abrangência do referido princípio, recorre-se ao entendimento de Themístocles Cavalcanti, que considera a livre iniciativa sob o aspecto do free interprise norte americano, enfatiza assim algumas características que norteiam a hermenêutica deste sob a égide da apropriação privada, particular da propriedade dos bens de produção e consumo; a aceitação ética e econômica do princípio firmado na finalidade lucrativa empresarial; a admissão da concorrência como efetivação da maior eficácia negocial e a certeza do mínimo intervencionismo, para o fomento de mais oportunidades no âmbito econômico (CAVALCANTI, 1997, p. 257).

Compreendendo a vasta importância e alcance do princípio da livre iniciativa, admite-se assim, que a livre concorrência, seja considerada, nesse sentido, um desdobramento ou complemento deste, se considerar a livre concorrência como livre jogo das forças de mercado, na disputa da clientela, ou seja, prevê desigualdades advindas do jogo, mas parte de um pressuposto jurídico formal na competição limitada a parâmetros de coibição de injustiças.

Desde modo, atrelando a livre concorrência ao significado de liberdade em toda sua forma, não restaria dúvidas da livre inciativa como escopo geral de amparo a livre concorrência. Ademais, a concepção aqui aduzida, não desmembra a correlação temática dos dois princípios, já que, por vezes, estão interligados no núcleo geral econômico constitucional.

Outrora, deve-se compreender a abrangência da livre concorrência, como dogmática da atuação Estatal no âmbito econômico, seja para coibição de monopólios, para o delineamento das disposições dos agentes de mercado, ou para proteção das tutelas de liberdades ínsitas a livre inciativa.

Cabe, portanto, salientar a astúcia do legislador constituinte, em trazer separadamente os princípios com o objetivo de conceder a importância do máximo de contingências que emanam de sua previsão.

Nesse sentido, a livre concorrência rege a liberdade de concorrência como mecanismo de garantia de eficiência de um legitimo sistema de mercado, por meio da tutela de abertura jurídica de ingresso aos particulares para competirem em atividades lícitas sob condições de igualdade, além de limitar e regular a intervenção do Estado necessária para tanto, com a finalidade de alcance ao desenvolvimento nacional atrelado ao social.

Além dos ajustes de êxito econômico, tal princípio "tem como centro de suas atenções o consumidor, considerado como parte vulnerável da relação de consumo a merecer a proteção jurídica promovida, em parte, pela tutela da livre concorrência" (TAVARES, 2013, p. 41). Eis que o benefício aos consumidores se faz inevitável, pois os reflexos que derivam das medidas de regulação de mercado, por meio da coibição de arbitrariedades, na ânsia de um mercado com justa competição, incidem diretamente sobre eles.

Nessa linha, Celso Ribeiro Bastos (1998, p. 456) compreende a amplitude da livre concorrência e sua importância, afirmando que:

\begin{abstract}
[...] a livre concorrência hoje, portanto, não é só aquela que espontaneamente se cria no mercado, mas também aquela outra derivada de um conjunto de normas de política econômica. Existe, portanto, o que pode ser chamado um regime normativo da defesa da concorrência voltada ao restabelecimento das condições do mercado livre. 0 princípio constitucional autoriza esta sorte de intervenção ativa no mercado, sem falar na negativa consistente na eliminação das disfunções e imperfeições.
\end{abstract}

Assim sendo, percebe-se que embora previsões individuais imprescindíveis à ordem econômica, a livre iniciativa e a livre concorrência se correlacionam, de modo que não se confundem, mas se harmonizam na seara das tutelas de liberdades, enquanto para uma em âmbito individual, para outra no sentido coletivo, ambas tuteladas pelo estado.

No tocante, consolida-se a admissão da Constituição à intervenção estatal norteada normativamente e principiológicamente na mais vasta compreensão 
destes institutos, para garantia de um legítimo sistema econômico de mercado, preservado os interesses dos agentes empresariais em ambiente de liberdade, portanto regulado pela livre concorrência, compreendendo que "as leis de mercado determinarão as circunstancias em que haverá ou não o êxito do empreendedor (livre iniciativa)" (TAVARES, 2013, p. 40).

Ademais, tais princípios relacionam-se a exigência de que a ordem econômica assegure igualdade, pluralidade de agentes, atividades e diminuição das distorções e abusos de mercado, e não planificação de mercado. Cabe salientar que o objetivo do presente estudo é delinear o princípio da livre iniciativa e livre concorrência com a finalidade de verificar suas implicações na seara concretiva, por meio de dispositivos legais que os efetivem.

\section{MECANISMOS DE EFETIVIDADE}

Admitida à intervenção mínima estatal, ancorada sob os prismas constitucionais, em especial no que cerne os princípios norteadores da ordem econômica, quanto a livre iniciativa e livre concorrência, com a finalidade de "assegurar a todos a existência dignidade, conforme os ditames da justiça social"2. Denota-se o papel assecuratório que emanam as medidas a serem adotadas para concreção da matéria.

Nesse tocante, além de regência das premissas princiológicas, o artigo 173, da Constituição Federal (BRASIL, 1988) prevê a repressão ao abuso ao poder econômico, estabelecendo de forma contundente:

Art. 173 - Ressalvados os casos previstos nesta Constituição, a exploração direta de atividade econômica pelo Estado só será permitida quando necessária aos imperativos da segurança nacional ou a relevante interesse coletivo, conforme definidos em lei. [...]

$\S 4^{\circ}$ - A lei reprimirá o abuso do poder econômico que vise à dominação dos mercados, à eliminação da concorrência e ao aumento arbitrário dos lucros. (Grifo do autor).

2. Art. 170. A ordem econômica, fundada na valorização do trabalho humano e na livre iniciativa, tem por fim assegurar a todos existência digna, conforme os ditames da justiça social, observados os seguintes princípios [...]
Ora, evidenciam-se, dentro da própria Constituição, os limites ao intervencionismo estatal, e ao controle de mercado, em consonância aos princípios, em prol da legitimidade da ordem econômica à medida que a interferência só se consolida no que pese a ameaça as premissas normativas.

Ressalta-se que na esfera constitucional o tema possui importante proteção, deste modo, para se operacionalizar a defesa da concorrência também infra constitucionalmente, em 1994 foi criada a Lei Antitruste Brasileira, ou seja, legislação em defesa da concorrência que visa tutelar as estruturas de mercado, tal legislação já existe conceitualmente em diversos outros países, que buscam inibir e coibir abusos ao poder econômico.

No ordenamento Brasileiro essa se apresenta sob o $\mathrm{n}^{0} 8.884$, de 94, que teve diversos dispositivos revogados pela lei $n^{0} 12.529$, de 30 de novembro de 2011 e se justifica como corolário dos princípios da ordem econômica, uma vez, que se consolidam como estrutura normativa de controle as concentrações econômicas que desequilibram o mercado. A legislação mais atual assim dispõe sobre o objetivo a que foi proposta:

\begin{abstract}
Art. $1^{\circ}$ Esta Lei estrutura o Sistema Brasileiro de Defesa da Concorrência - SBDC e dispõe sobre a prevenção e a repressão às infrações contra a ordem econômica, orientada pelos ditames constitucionais de liberdade de iniciativa, livre concorrência, função social da propriedade, defesa dos consumidores e repressão ao abuso do poder econômico.

Parágrafo único. A coletividade é a titular dos bens jurídicos protegidos por esta Lei. (BRASIL, 2011, s.n.p.)
\end{abstract}

O Sistema Brasileiro de Defesa da Concorrência tem sua formação definida no bojo da lei 12.529/11 que inclui o CADE e a Secretaria de Acompanhamento Econômico do Ministério da Fazenda, com as atribuições previstas no próprio dispositivo em questão.

Conselho Administrativo de Defesa da Concorrência

Ressalta-se o fato de que pela lei no 8.884/94 (BRASIL, 1994) o CADE, foi transformado em autarquia federal vinculada, de modo indireto, ao $\mathrm{Mi}$ nistério da Justiça, tal órgão dispõe a respeito da ordem econômica, tanto sobre prevenção quanto a 
repressão de infrações em consonância com a disposição da Lei Antitruste.

Dada o significado objetivo da Lei Antitruste na coibição e repressão do abuso do poder econômico, que na prática se evidencia, com formação de monopólios, carteis, dumpings, holdings, consórcios e em outras inúmeras possibilidades, faz-se importante frisar a importância de efetividade das disposições legais, aqui enunciadas.

O CADE, por ser autarquia federal é responsável no âmbito do Poder Executivo, pela prevenção e repressão aos abusos a livre concorrência, além de assumir caráter educacional ou pedagógico sobre essa cultura de mercado, vez que, preventivamente atua, fazendo análise e decisões sobre incorporações, fusões econômicas empresarias dentre outras táticas de mercados que possam ser desenvolvidas por grandes empresas, repressivamente julga condutas nocivas à livre concorrência, além de atuar na instrução do público sobre as condutas que possam afetar a livre concorrência, no incentivo e estímulo a pesquisas acadêmicas na área, fomento de palestras, cursos, cartilhas dentre outros.

Considera-se por bem, que a Lei Antitruste consolida a eficácia constitucional a que se refere a ordem econômica. Nesse sentido "conferem concreção aos princípios da liberdade de iniciativa, da livre concorrência, da função social da propriedade, da defesa dos consumidores e da repressão ao abuso do poder econômico" (GRAU, 2010, p. 234) ou seja, pela consonância com a ideologia constitucional de 1988.

A Legislação Antitruste trouxe disposições de cunho preventivo e repreensivo já presentes na lei de 94 e reafirmada na atual conjuntura legal de 2011, a primeira no tocante ao controle, por parte de órgãos de defesa da concorrência a operações de grande porte como forma de evitar monopólios e atos de concentração que possam impactar o cenário concorrencial, desse modo, em seu bojo regula controles, por meio de submissão dos atos de concentração para avaliação dos órgãos de defesa da concorrência, além da previsão do compromisso de desempenho, tais medidas trazem caráter repressivo justamente por regula- mentar a desconstituição da operação abusiva.

No tocante a vertente de repreensão, esta, por sua vez, fica a cargo da penalidade às práticas anticompetitivas por empresas que exerçam poder de mercado, tais práticas têm seus efeitos previstos no Capítulo II, denominado “Das Infrações” da lei 12.529/11, no artigo 36, que inclui em seu rol exemplificativo atos de que prejudiquem a livre concorrência ou a livre iniciativa, dentre outros que elucidem a dominação de mercado, ou seja, que por fim ensejem desigualdades (BRASIL, 2011).

A prática de infração à ordem econômica sujeita os responsáveis às penas de natureza pecuniária e não pecuniária, o que denota a intenção do legislador de desestimular práticas lesivas à concorrência.

Ademais, a atuação do judiciário, também, se faz necessária quando da omissão dos órgãos como o CADE e as agências reguladoras, como suporte a atuação desses, destarte, limitada a devida interferência na esfera de atuação dos órgãos que compõe o Sistema Brasileiro de Defesa da Concorrência, para não cometer violação aos princípios da legalidade e da separação dos poderes.

Sem adentrar na esfera da separação dos poderes, quanto à intervenção estatal, bem como todos seus reflexos, faz-se necessário esclarecer que no caso das decisões realizadas pelo CADE, essas, são passiveis de apreciação do Judiciário, sempre que venham acarretar lesões a direitos subjetivos.

Certo, é que o Poder Judiciário deve ser reconhecido nesse caso, não em sua tendência de ativismo judicial, mas como um órgão reparador das possíveis lesões ou ameaças executadas pelo Poder Executivo, portanto, revisor judicial sobre as decisões do CADE. Hodiernamente, mais um mecanismo de efetividade das máximas intrínsecas aos princípios ora esboçados da livre iniciativa e livre concorrência.

Ademais, percebe-se que as leis brasileiras, avaliadas pela sistemática constitucional, buscam a harmonia entre os dispositivos legais, deste modo, resta caracterizado um ordenamento rico no respaldo à Ordem Econômica. O desafio, portanto é encontrar sintonia desses mecanismos sob o prisma de efetividade dos princípios livre iniciativa e livre concorrência. 
Destarte não há que se falar em respaldo de leis anticoncorrenciais, sem consonância e amparo dos princípios ora mencionados, uma vez que, as leis infraconstitucionais, instrumentalizam a aplicabilidade desses, com a finalidade de assegurar a todos o direito de livre participação em atividades empresariais, pautado na justiça social.

Sem desconsiderar de fato, as dificuldades de controle de mercado e a busca deste como ideário, nesse sentido anota Celso Ribeiro Bastos (1998, p. 80):

Embora de fato o mercado possa não reproduzir condições ideais, perfeitas de competição, é forçoso reconhecer, no entanto, que ainda assim é plenamente possível uma concorrência relativa, que, nada obstante uma certa dose de restrição, esteja apta a produzir todas aquelas vantagens próprias da concorrência.

Portanto, o que se despende é que os mecanismos que entoam com a competição calcada na liberdade e igualdade ínsitas aos princípios da livre concorrência e livre iniciativa, executados pelo Estado, constituem a eficácia jurídica, e mais que isso, a eficácia de preceitos Constitucionais, que visam o bem da coletividade.

\section{CONSIDERAÇÕES FINAIS}

A proposta do presente trabalho foi responder ao questionamento que cerne a efetiva conjugação entre os princípios constitucionais da livre iniciativa e livre concorrência como elemento fundamental ou mera enunciação legal, para demonstrar a importância destes para a manutenção da Ordem Econômica.

Por todo exposto resta evidenciado que, mais que base principiológica que norteia a Ordem Econômica, tais princípios representam o marco para qualquer transação ou ajustes mercadológicos, que interfiram no modelo econômico adotado.

Portanto, não perfaz mera enunciação legal a concreção aos princípios basilares, certo que, a livre iniciativa e livre concorrência para se efetivarem possuem amparo de especificidades legislativas infraconstitucionais, como exemplo a lei antitruste, e apoio dos órgãos envoltos ao controle, combate e manutenção do mercado concorrencial.

Resultado dessa observância tem-se o amparo legislativo quanto à admissão do intervencionismo estatal na economia que não é facultativo, mas possível desde que calcado no mínimo legal e necessário. Tal admissão se funda em detrimento dos princípios constitucionais ora abordados, além das previsões de coibição aos abusos de poder econômico, também, para a iniciativa privada, efetivado pelo Sistema Brasileiro de Defesa da Concorrência tem sua formação definida, formado pelo Conselho Administrativo de Defesa Econômica e a Secretaria de Acompanhamento Econômico do Ministério da Fazenda.

Desponta-se, por fim, deixar claro que não se retingem tais previsões a esfera de ideário, pois os princípios da livre iniciativa e livre concorrência são concretizados tanto pela força da Lei Maior, quanto pelo respaldado por meio de normas infraconstitucionais piamente válidas e que devem ser observadas para atingirem máxima efetividade, inclusive para conferir força política à Constituição, não permitindo ao aplicador da lei alegar desamparo legal para tanto.

Desta feita, o lastro da consolidação dos princípios da livre iniciativa e livre concorrência por meio da dinamização do mercado, valorização do consumidor, respeito a liberdade de atuação, limitação ao intervencionismo e pela igualdade de desempenho, se faz essencialmente imperioso e admissível. Ademais, não se trata de um direito absoluto, mas sim, de garantia ao cogente papel do Estado, que se propõe a minimizar impactos no âmbito econômico e jurídico e social.

\section{REFERÊNCIAS}

\author{
BASTOS, Celso Ribeiro. Curso de Direito Constitu- \\ cional. São Paulo: Saraiva, 1998.
}

\section{BRASIL. Constituição da República dos Estados}

Unidos do Brasil, 1891. Disponível em: <http://www. planalto.gov.br/ccivil_03/constituicao/constituicao91.htm>. Acesso em: 6 jun. 2014. 
BRASIL. Constituição da República dos Estados Unidos do Brasil, 1934. Disponível em: <http://www12. senado.gov.br/orcamento/documentos/outros/linha-do-tempo/Constuicao_Republicana_de_1934.pdf>. Acesso em: 6 jun. 2014.

\section{BRASIL. Constituição da República dos Estados}

Unidos do Brasil, 1946. Disponível em: <http://www. planalto.gov.br/ccivil_03/constituicao/constituicao46.htm>. Acesso em: 6 jun. 2014.

\section{BRASIL. Constituição da República dos Estados}

Unidos do Brasil, 1988. Disponível em: <http://www. planalto.gov.br/ccivil_03/constituicao/constituicao. htm>. Acesso em: 6 jun. 2014.

BRASIL. Lei 12.529 de 30 de novembro de 2011. Disponível em: <http://www.planalto.gov.br/ccivil_03/_ ato2011-2014/2011/Lei/L12529.htm>. Acesso em: 6 jun. 2014.

BRASIL. Lei $\mathbf{8 . 8 8 4}$ de 11 de junho de 1994. Disponível em: <http://www.planalto.gov.br/ccivil_03/leis/ 18884.htm>. Acesso em: 6 jun. 2014.
CAVALCANTI, Themístocles Brandão. Manual da Constituição. Rio de Janeiro: Zahar, 1997.

CORVAL, Paulo Roberto dos Santos. Os valores sociais da livre iniciativa. Disponível em: <http://www2. senado.leg.br/bdsf/bitstream/handle/id/92842/Corval\%20Paulo.pdf>. Acesso em: 3 de jun. 2014.

GRAU, Eros Roberto. A ordem econômica na Constituição de 1988. São Paulo: Malheiros, 2010.

PETTER, Lafayete Josué. Princípios Constitucionais da Ordem Econômica. São Paulo: Revista dos Tribunais, 2005.

RAGAZZO, Carlos Emmanuel Joppert. Notas Introdutórias sobre o princípio da Livre Concorrência. Revista Scientia Iures. 2006. Disponível em: <http:// www.uel.br/revistas/uel/index.php/iuris/article/ view/4110/3538>. Acesso em: 2 jun. 2014.

TAVARES, André Ramos. Direito constitucional Econômico. São Paulo: Método, 2003.

TAVARES, André Ramos. Direito constitucional da Empresa. São Paulo: Método, 2013. 
Recebido em: 20 de Agosto 2015 Avaliado em: 23 de Agosto de 2015 Aceito em: 11 de Setembro de 2015
1. Graduada em Direito e em Ciências Sociais, MBA em Desenvolvimento Regional Sustentável, atualmente Mestranda em Direito pela Universidade de Marília - UNIMAR. E-mail: masemeghini@bb.com.br

2. Mestranda em Direito pela Unimar, Graduada em Direito. E-mail: email@adeneele.com 